\title{
Prevention and Control of Hospital-Related Infections in Low and Middle Income Countries
}

\author{
Lul Raka*
}

Faculty of Medicine, University of Prishtina \& National Institute of Public Health of Kosova, Prishtina, Kosova

\begin{abstract}
Hospitals are the main health facilities for the risk of acquiring an infection during the delivery of care. Hospital-related infections constitute an important health challenge worldwide. In low and middle income countries infection prevention and control policies are either non-existent, poorly adapted or insufficiently funded by governments. Lack of financial funds, inadequate infrastructure and management, improper use of antimicrobials and shortage of trained staff are key constraints for effective infection control in the hospitals of low income countries. As a consequence, these countries are facing the challenges of higher rates of hospital infections, frequent outbreaks, unsafe care and spread of infections in the community. The best solutions for an effective infection control program entail introduction of prevention bundles, greater governmental commitment, improvement of compliance with hand hygiene, surveillance, prudent use of antimicrobials, translation of research results into practice and upgrading the capabilities of microbiology laboratory. Focusing on infection control, countries with limited resources can improve the quality of healthcare in the future.
\end{abstract}

Keywords: Hospital-related infections, low and middle income countries, prevention.

\section{INTRODUCTION}

Hospital-related infections (HRIs) constitute an important health challenge worldwide. In low and middle income countries (LMIC) this challenge is more highlighted because disease prevention and control policies are either nonexistent, poorly adapted or insufficiently funded by governments [1,2]. The rates of HRIs within a hospital represent the best indicator for the quality of services offered, where a high frequency of HRIs is evidence of a poor quality of health service delivery.

Hospitals are main facilities for the risk of acquiring an infection during the delivery of care. Therefore infection control and prevention activities are focused mainly at the hospital level. But, since their occurrence is increasing in outpatient clinics and in nursing homes, nowadays term hospital related infections is used interchangeably with the term health care-associated infections (HAI) or previously nosocomial infections.

Hospital infection is defined as an infection occurring in a patient during the process of care in hospital, which was not present or incubating at the time of admission [3]. Hospital infections include iatrogenic infections, which are related to health-care worker's errors during health care and also occupational infections among staff of the facility. The time frame for diagnosis of a HRIs is at least 48 hours after hospital admission, 3 days after hospital discharge, within 30 days after an operative procedure or one year after implants.

HRIs are the most frequent in intensive care units and acute care surgical wards. Intensive Care Units (ICU) treat a

*Address correspondence to this author at the Rrethi i spitalit, p.n., 10000 Prishtina, Kosova; Tel: +37744368289; Fax: +38138 550 585;

E-mail: lulraka@hotmail.com minority of patients, but have the highest incidence of HRIs [4]. Infection rates even in highly resourced units ranged from $25-35 \%$ with mortality exceeding $25 \%$.

HRIs pose a significant risk not only for patients, but also for health-care workers, students and visitors. Definitions proposed by Centers for Disease Control and Preventions (CDC) to define an infection as hospital acquired are widely used throughout the world [5].

Many different bacteria, viruses, fungi and parasites may cause HRIs, with multiresistant bacteria being predominant [6]. There are two groups of bacteria causing HRIs: (1) commensal bacteria (endogenous), which are part of the normal flora and cause infections if the natural host is compromised (cutaneous coagulase-negative staphylococci and Gram-negative bacteria in the digestive tract) and (2) pathogenic bacteria (exogenous), which are more virulent and cause infections regardless of the host immune status methicillin resistant $S$. aureus (MRSA), Vancomycin resistant Enterococci(VRE) and Gram-negative bacteria producing extended spectrum beta-lactamases (ESBL). Some bacteria survive well in the hospital environment such as water, damp areas and even in sterile products or disinfectants (Pseudomonas spp., Acinetobacter spp, etc.). Microorganisms can be transmitted within health care facilities by several routes: direct contact, droplet contact (respiratory route) or vehicle transmission.

Many factors have been shown to be associated with the risk of acquiring HRIs. These factors can be related to the infectious agent, host and environment. The most important risk factors for acquiring infections in the hospital include underlying disease, invasive diagnostic-therapeutic procedures and improper use of antimicrobials.

HRIs can affect any part of the body, but most frequent are urinary tract infections associated with use of urinary 
catheters, followed by respiratory tract infections related to mechanical ventilation, bloodstream infections derived from intravascular devices and wound infections after surgical interventions or trauma.

HRIs impact on the population in many ways. They affect patients directly, causing increased morbidity and mortality; they may lead to disability and may reduce quality of life [7]. They also impact on the healthcare system by extending hospitalization of affected patients and driving up the costs of diagnosis and treatment. HRIs may be transmitted from healthcare settings into the community, decreasing the reputation of healthcare institutions in the eyes of the public. They also may be a subject of indictment by the treated patients in hospitals.

\section{HOSPITALS IN LOW AND MIDDLE INCOME COUN- TRIES-CONSTRAINTS AND OUTCOMES}

Country economies are divided among income groups according to 2008 gross national income (GNI) per capita, calculated using the World Bank Atlas method [8]. The groups are: low income, $\$ 975$ or less; lower middle income, \$976-3,855; upper middle income, \$3,856-11,905; and high income with $\geq \$ 11,906$. Low-income and middle-income economies are sometimes referred to as developing economies. These economies represent 144 of 209 countries of the world $(68.8 \%)$ and more than $75 \%$ of the world population. There is limited information regarding association between socio-economic level of countries and HRIs.

Prevention and control in low and middle income countries differs substantially from that in the developed world with high income. Limited resources represent the main challenge for governments in LMIC [9]. Priority in the allocation of funds is often directed to visible targets within society such as schools, infrastructure and security. Healthcare frequently is far behind. Even in countries where the healthcare budget is given high priority, the proportion devoted to prevention of HRIs is usually insufficient. Resources and incomes are unequally distributed throughout the world. The richest $20 \%$ of the world's population have $74 \%$ of the income, whereas the poorest $20 \%$ of the world's population have only $2 \%$ [10]. Poverty, war, economic and political disturbances all significantly increases HRIs [11]. During the last few decades, infection control activities in LMIC have increased, particularly in South America, South East Europe and countries of the former Soviet Union [12]. Public pressure to improve the quality of hospital care, the increased cost of HRIs in healthcare systems, the emergence of multiresistant microorganisms, the approach of occupational hazards have played an important role in this development.

Health systems in LMIC are hospital-dominated, with $50-80 \%$ of resources allocated to hospitals in urban centres, which often have tertiary academic affiliations. On the other hand a large number of people present to the other county hospitals, which have inadequate resources, staff training, and motivation with an impact on the health of millions of people [13].

In many hospitals of LMIC adequate supplies to control infection of normally sterile body sites, mucous membranes and non-intact skin are not available. Patients and their families may be required to provide care materials such as syringes, surgical gowns, and drugs. Moreover, compliance with hand hygiene is often low. Overcrowding and understaffing, particularly in ICU, results in decreased hand hygiene compliance; frequent movement of patients and staff between hospitals wards results in an increased risk of transmission of multidrug-resistant microorganisms [14]. Such transmission is often exacerbated by overcrowding, with patients sometimes sharing beds and supplies. There may be a lack of commitment to healthcare by policy-makers in the developing world and allocation of funds is often disproportionate to the priorities set by providers. Corruption and nonformal payments are frequent. Information systems are not fully developed. There are limited grants available for research and no legislation mandating accreditation of hospitals or infection control programmes. In-service training for employees is highly variable and often minimal. Transfusion and injections may pose a risk for transmission of HIV and hepatitis [15]. Many other problems abound; for example, sterilisation departments are not centralised and there is lack of quality control in disinfection and sterilisation.

Although many hospitals in the LMIC may have infection control programmes and committees on paper, in practice they barely exist. Inadequate numbers of trained personnel work in infection control, and face continual resistance from clinical staff. In addition, inadequate salaries lower the healthcare workers' motivation. This litany of problems means that the response to common outbreaks of disease in high risk units by management and staff is mainly reactive rather than proactive. Lack of ongoing surveillance results in delays in detecting outbreaks, with increasing costs and mortality.

In addition to mentioned constraints, frequent malnutrition and other types of infection and diseases contribute to increase the risk of HRIs in LMIC.

As a result of the weakness and problems outlined above, LMIC face the challenge of high rates of HRIs and frequent outbreaks. Between $5 \%$ and $10 \%$ of human immunodeficiency virus (HIV) infections worldwide are transmitted through transfusion of contaminated blood and blood products. Over 16 billion injections are administered each year in LMIC and the proportion of injections given by syringes and needles that are reused without sterilisation ranges from 1.5 to $69.4 \%$ [16]. Unsafe injections alone are estimated to cost the world US\$ 535 million in direct medical costs [17]. Improper waste disposal is present in 18$64 \%$ of health care facilities of LMIC [18].

The 2000 Global Burden of Disease study, death and disability from injection-associated infections by hepatitis $B$ virus (HBV), hepatitis $\mathrm{C}$ virus (HCV) and HIV revealed that patients received an average of 3.4 injections per year, $39.3 \%$ of which were given with reused equipment. Contaminated injections caused an estimated 21 million HBV infections, 2 million HCV infections and $260000 \mathrm{HIV}$ infections, accounting for $32 \%, 40 \%$ and $5 \%$, respectively, of new infections [19]. Another consequence of insufficient infection control infrastructure is the spread of multidrugresistant organisms, such as MRSA, VRE, extendedspectrum $\beta$-lactamase-producing Gram-negative bacilli, multidrug-resistant Mycobacterium tuberculosis and fluconazole-resistant Candida spp. 


\section{THE BURDEN AND COSTS OF HOSPITAL RELA- TED INFECTIONS}

In low and middle income countries the picture of the burden of HRI is unknown due to lack of reliable data and the use of different definitions and methodologies. Many LMIC have not conducted any surveillance studies regarding HRIs and few studies provide information on etiology and risk factors for HRIs.

HRIs represent one of the commonest complications of healthcare, affecting around 2 million persons admitted to acute hospitals annually [20]. They complicate $5-10 \%$ of admissions to acute care hospitals in industrialised countries. Average prevalence of HRI in Europe is 7.1 with range 3.5$14.8 \%$ [21]. By contrast, HRIs occurred in $>40 \%$ of hospitalisations in developing countries in Asia, Latin America, and sub-Saharan Africa [22]. The first worldwide prevalence survey of HRIs conducted under the auspices of World Health Organization (WHO) in 55 hospitals of 14 countries in WHO regions showed an average incidence of $8.7 \%$ [23]. The majority of HRIs relate to medical devices, e.g. pneumonia - related to mechanical ventilation, urinary tract infections (UTIs) - to urinary catheters, surgical site infection (SSI) after trauma or surgery, and bacteraemia derived from intravascular devices. UTIs constitute $30-40 \%$ of all HRIs. In intensive care of LMIC $66 \%$ of patients admitted to ICU develop HRIs. Table 1 compare deviceassociated infections (DAI) rates (per 1000 device-days) in the ICUs of the low income countries participating in International Nosocomial Infection Control Consortium (INICC) and the U.S. National Healthcare Safety Network (NHSN)[24].

Epidemiological surveillance of HRIs has been standardised by the Centers for Disease Control and Prevention (CDC) National Nosocomial Infections Surveillance (NNIS) system, providing definitions for DAIs [5]. Surveillance and calculation of DAI rates of infection per 1000 invasive device-days allows analysis and impact of specific risk factors and guide targeted interventions. Ventilator-associated pneumonia (VAP) is a leading cause of death in hospitalised patients. A meta-analysis of articles concerning VAP in developing countries in MEDLINE (January 1966 to April 2007) showed rates from 10 to 41.7 per 1000 ventilator-days; crude mortality ranged from $16 \%$ to $94 \%$ and with increased length of stay in ICU [25].

Many studies have shown the importance of HRIs among neonates in LMIC, where an average of 4384 children die every day of these infections. In a major review, reported rates of neonatal infections were 3-20-fold higher than those reported in industrialised countries [26]. Neonatal infections are estimated to cause 1.6 million deaths e annually, $40 \%$ of all neonatal deaths in developing countries [27].

The costs of HRIs are substantial everywhere, although they varies between countries due to different health care systems. Jarvis showed an estimated average cost of (US) $\$ 558$ to $\$ 593$ for each UTI, $\$ 2,734$ for each SSI, $\$ 3,061$ to $\$ 40,000$ for each bloodstream infection, and $\$ 4,947$ for each case of pneumonia [28]. In countries with prospective payment systems based on diagnosis- related groups, hospitals lose from $\$ 583$ to $\$ 4,886$ for each HRI. Annual economic impact of HRIs in Europe is about 7 billion euro per year. The cost to the government of Trinidad and Tobago for HRIs was estimated at $\$ 697,000$ annually. In Mexico, the annual cost approaches $\$ 1.5$ billion, and in Thailand $10 \%$ of the annual hospital budget is spent on HRIs [29]. Some investigators have attempted to measure costs related to hospital outbreaks of HRIs caused by multiresistant organisms. In a study of infections caused by MRSA it was estimated that average cost was $\$ 4000$ per infection, whereas costs of $C$. difficile-associated diarrhea was approximately $\$ 4500$ per patient [30].

\section{ANTIMICROBIAL RESISTANCE}

Resistance to antimicrobial agents is a global challenge in all healthcare facilities. The globalization enabled the rapid spread of multiresistant microorganisms [31]. In LMIC inappropriate and uncontrolled use of antibiotics is very common and antimicrobials are frequently available over the counter in pharmacies. In many low income countries resistance among common pathogens to cheap antimicrobials has already increased drastically, resulting in limited effectiveness. The quality and potency of antibiotics are often suspected, with unregulated import, registration and distribution. Another factor contributing to resistance is lack of antibiotic policies or basic recommendations at governmental level or within hospitals. Between $20 \%$ and $50 \%$ of a hospital budget is spent on antimicrobials, which are used to treat more than half of all patients. Even in developed countries $>50 \%$ of antimicrobials are prescribed incorrectly, either administered in suboptimal doses or for incorrect duration [32]. Misuse has been identified as an important factor in the emergence of antimicrobial resistance [33]. In turn, this resistance makes the clinical management of the patients more difficult.

The use of antimicrobials in the veterinary area had an important impact on increase of antimicrobial resistance. Table 1 presents overview of antimicrobial reisstance rates in ICU between INICC and NNIS system. The frequencies of resistance of Staphylococcus aureus isolates to methicillin (MRSA) $(80.8 \%$ vs $48.1 \%)$, Enterobacter species to ceftriaxone $(50.8 \%$ vs $17.8 \%)$, and Pseudomonas aeruginosa to fluoroquinolones (52.4\% vs $29.1 \%$ ) were also far higher in the Consortium's ICUs.

\section{SOLUTIONS AND PERSPECTIVES FOR PREVENT- ION AND CONTROL}

The prevention and control of HRIs requires a triangle partnership between HCW, government and community. Most HRIs can be prevented with readily available and relatively inexpensive strategies. The Study on the Efficacy of Nosocomial Infection Control in 1974 showed that effective infection control programmes could reduce infection rates by as much as $32 \%$ and be cost-effective [34]. In an overview of published reports on the effect of infection control programmes from 1990 to 2002, Harbarth et al. found that between $10 \%$ and $70 \%$ of HRIs were preventable [35]. In the Hospital Sao Paulo in Brazil, there was a $71 \%$ decline in all HCAIs in the ICU when an infection control programme was implemented, saving about US \$2 million [36]. Many other successful strategies have been documented. 
Table 1. Comparison of Antimicrobial Resistance Rates (\%) in the ICUs of the International Nosocomial Infection Control Consortium (INICCC) and the U.S. National Nosocomial Surveillance System (NNIS) [24]

\begin{tabular}{|c|c|c|}
\hline & $\begin{array}{c}\text { Pooled Mean (Range) } \\
\text { (Interquantile Range, 25-75\%) }\end{array}$ & $\begin{array}{c}\text { Pooled Mean (Range) } \\
\text { (Interquantile Range, 25-75\%) }\end{array}$ \\
\hline \hline Antibiotic resistant pathogen & INICC 2002-2007 NNIS 1992-2004 \\
\hline Methicillin-resistant Staphylococcus aureus (MRSA) & $80.8(50.0-100.0)$ & $52.9(32.7-603)$ \\
\hline Methicillin-resistant coagulase-negative staphylococci & $75.2(64.0-100.0)$ & $76.6(69.4-83.8)$ \\
\hline Vancomycin-resistant enterococcus species & $9.4(0.0-6.3)$ & $13.9(5-24.3)$ \\
\hline Ciprofloxacin/ofloxacin-resistant Pseudomonas aeruginosa & $52.4(40.0-75.0)$ & $34.8(17.4-41.3)$ \\
\hline Imipenem-resistant P aeruginosa & $36.6(0.0-52.4)$ & $19.1(8.3-25.5)$ \\
\hline Ceftazidime-resistant P aeruginosa & $51.7(33.3-72.7)$ & $13.9(5-16.9)$ \\
\hline Piperacillin-resistant P aeruginosa & $50.8(36.4-75.0)$ & $17.50(7.5-19.5)$ \\
\hline Ceph3-resistant Enterobacter species & $56.8(30.8-80.0)$ & $27.70(17.4-36.4)$ \\
\hline Carbapenem-resistant Enterobacter species & $8.5(0.0-0.0)$ & $0.70(0.0-0.0)$ \\
\hline Ceph3-resistant Klebsiella pneumoniae & $68.2(33.3-85.7)$ & $6.20(0.0-8.0)$ \\
\hline Ceph3-resistant Escherichia coli & $53.9(11.1-80.0)$ & $1.3(0.0-2.6)$ \\
\hline Ciprofloxacin/ofloxacin-resistant E. coli & $42.6(12.7-78.9)$ & $7.30(0.0-8.2)$ \\
\hline
\end{tabular}

Most countries address the problem of HRIs differently. As healthcare systems vary widely, so preventive strategies must be designed accordingly.

\section{Government and Managerial Support}

In low-income countries, the risk of patients and HCWs acquiring HRIs could be significantly reduced if governments make infection control a high priority. Administrative controls are amongst the most important steps in prevention and control of HRIs. Therefore a political support and commitment is essential in effectiveness of all other measures. National authorities must understand that without the proper resources, hospitals can be high risk areas. Therefore healthcare authorities must establish and support a comprehensive, effective national programme. Such a programme should set national objectives, and develop strategies, guidelines and policies for specific infection control issues, which are regularly updated. Many countries already have such programmes. If these programmes are not available, those from the developed world should be adopted. Since LMIC have their own characteristic problems, these must be taken into account when formulating recommendations and policies [38].

Due to their contact with patients or infected material from patients, many healthcare workers are at risk for exposure and possible transmission of infectious agents. Therefore occupational health and immunisation of HCWs is an essential part of prevention and infection control programmes [39]. Moreover, education of $\mathrm{HCWs}$ and behavioural models complete the mosaic for prevention and control of HRIs.

\section{Hand Hygiene}

Hand hygiene remains the simplest and the primary measure to prevent HCAI and reduce spread of multidrugresistant organisms. Although hand hygiene is a simple measure, the lack of compliance among healthcare workers is problematic worldwide, averaging $<40 \%$ [40]. In 2002, the CDC recommended the use of alcoholic hand rubs which have the advantage that they can be placed at the bedside [41]. Also, where hand-washing facilities are primitive or scarce, it is often easier to provide a hand rub than sinks with running water and a functioning sewage system. Introduction of alcohol- based hand rub has led to increased hand hygiene compliance among healthcare workers and fewer HRIs [42]. In some LMIC, implementation of education, process surveillance, and performance feedback has considerably enhanced hand hygiene compliance [43].

\section{Surveillance}

Surveillance is an essential component in HRIs prevention, with the aims of outbreak identification, establishment of endemic baseline rates of infection and the evaluation of control measures [44]. Surveillance data can be used to identify preventable infections in high risk areas, so that resources are targeted to high priority areas. Surveillance of most important HRIs should be accompanied by surveillance of antimicrobial use and resistance pattern. There is good evidence that antibiotic stewardship programmes have been successful in modifying antimicrobial prescribing practices, resulting in most instances in reduction of use [45]. Unfortunately, such programmes are often lacking in developing countries, and antimicrobial resistance problems emphasise the importance of clinical microbiology laboratory services [46].

\section{The Bundle Approach}

Care bundles are part of a set of multiple intervention strategies to improve patient outcomes. They have been introduced in the USA by Institute for Healthcare Improvement (www.ihi.org) and through the Saving Lives initiative produced by the UK Department of Health as hight impact interventions (www.clean-safe-care.nhs.uk ). 
Bundles are directed generally at aseptic procedures that carry a high risk of HRI if not done properly. These usually represent a set of three to five practices that, when performed collectively, reliably, and continuously have been proven to improve patient outcomes. Bundles also incorporate a simple audit tool to check that they are being implemented. To meet the required level of prevention, multiple strategies must be implemented simultaneously [37]. The bundles are focused on the most important HRIs: catheter-associated bloodstream infection, catheter-associated UTI, ventilator-associated pneumonia and SSI.

\section{Global Initiatives: World Alliance for Patient Safety}

Improving the safety of patient care is now a global issue. A growing awareness of HRIs and patient safety prompted the World Health Organization (WHO) to promote the creation of the World Alliance for Patient Safety to coordinate, spread and accelerate improvements in patient safety [47]. Prevention of HCAI is the target of the Alliance's First Global Patient Safety Challenge, 'Clean Care is Safer Care', launched in October 2005. Implementation strategies include the integration of multiple interventions in the areas of blood safety, injection safety, clinical procedure safety, and water, sanitation and waste management, with the promotion of hand hygiene in healthcare as the cornerstone. The main target of the campaign is 'Five Moments for Hand Hygiene' approach. It defines the key moments for hand hygiene with united vision. Various tools and resources have been developed to complement the Five Moments approach including localised country specific tool [48].

\section{Research}

One measure to improve the knowledge base of infection control is through research and development. Research resources for addressing infection control problems of LMIC remain disproportionately low compared with the disease burdens borne by these countries. National economies in LMIC remains too weak to support research and development. Research activities are sporadic and marginal, based mainly on individual initiatives in the university sector and with almost no support from governments. There is a need to focus these limited resources on research that will optimize health benefits with cost-effective interventions. Research priorities of LMIC in the field of HRI are different compared to developed world. Research infrastructure should be focused on evaluating costs of HRIs, risk factors for developing HRI, hand hygiene, gather surveillance data on HRI, study on antibiotic consumption and resistance patterns and monitor impact of infection control programmes.

Publications from LMIC are increasing daily. An important window for research in developing countries arose through the International Nosocomial Infection Control Consortium (INICC). The INICC is the first multinational research network established to control HRIs in hospitals in limited-resource countries. It has developed from South American hospitals in 1998 to a dynamic network of 140 healthcare centers in 108 cities, from 36 countries of 4 continents. It is the only source of aggregate standardised international data on HRIs epidemiology in intensive care.
INICC published a surveillance study from January 2003 through December 2008 in 173 ICUs in Latin America, Asia, Africa, and Europe [24]. During the 6- year study, using CDC NNIS/NHSN definitions for device-associated healthcare-associated infection, prospective data were collected from 155,358 patients hospitalized in the consortium's hospital ICUs for an aggregate of 923,624 days. Although device utilization in the developing countries' ICUs was remarkably similar to that reported from U.S. ICUs in the CDC's NHSN, rates of device-associated nosocomial infection were 3-5 fold higher the ICUs of the INICC hospitals (Table 2).

The frequencies of resistance of $S$. aureus isolates and Enterobacteriaceae were also far higher in the Consortium's ICUs, and the crude unadjusted excess mortalities of devicerelated infections ranged from $23.6 \%$ (CVC associated $\mathrm{BSI}$ ) to $29.3 \%$ (VAP).

\section{Environment}

Isolation precautions with disinfection and sterilization comprise another important brick in the wall of infection control. Isolation precautions are important step in preventing transmission of infectious agents within the hospitals wards. Isolation systems enable health care workers to identify patients who need to be isolated and undertake appropriate precautions. In low income countries there is a lack of isolation rooms and usually patients with infections caused by same microorganisms are cohorted in same rooms. Personal protective equipment support achievement of this objective.

Important steps in prevention of HRIs are also introduction of validated processes for aseptic technique, decontamination, disinfection and sterilization of environment, soiled instruments and other items; and improving safety in operating rooms and other high risk areas [49].

\section{Infection Control Societies}

Many countries have not yet established infection control societies or associations, and general professional societies of physicians, nurses, and laboratory staff are not effectively engaged in infection control and prevention activities. The International Federation of Infection Control (IFIC) is an umbrella organisation of societies and associations of healthcare professionals in infection control and related fields worldwide including majority of them coming from LMIC. Currently IFIC has 66 members from 51 countries, and provides guidelines and educational material. Many regional and international networks throughout the world also participate in IFIC.

\section{Microbiology Laboratory Support for Infection Control}

Clinical microbiology laboratory plays a pivotal role in patient care providing information on a variety of microorganisms with clinical significance and is an essential component of an effective infection control program [50].

Laboratory plays important duties in prevention of HRIs, which include: surveillance of HRIs and antimicrobial resistance, rapid communication of laboratory data relevant to infection control, epidemiology typing of isolated pathogens, storing laboratory data and isolates, outbreak investigation and management, education of infection 
Table 2. Comparison of DAI Rates (Per 1000 Device-Days) in the ICUs of the International Nosocomial Infection Control Consortium (INICC) and the U.S. National Healthcare Safety Network (NHSN) [24]

\begin{tabular}{|c|c|c|}
\hline & $\begin{array}{c}\text { INICC } 2003-2008 \\
\text { Pooled Mean }(95 \% \text { CI })\end{array}$ & $\begin{array}{l}\text { U.S. NHSN 2006-2007 } \\
\text { Pooled Mean (95\%CI) }\end{array}$ \\
\hline \multicolumn{3}{|c|}{ CORONARY ICU } \\
\hline CAUTI & $4.4(3.5-5.3)$ & $4.4(4.1-4.8)$ \\
\hline VAP & $14.9(12.4-17.9)$ & $2.5(2.2-2.9)$ \\
\hline CLAB & $7.4(7.2-7.7)$ & $2.0(1.9-2.2)$ \\
\hline CAUTI & $6.1(5.9-6.4)$ & $3.3(3.1-3.5)$ \\
\hline VAP & $14.7(14.2-15.2)$ & $3.3(3.1-3.6)$ \\
\hline \multicolumn{3}{|c|}{ Pediatric ICU } \\
\hline VAP & $5.5(4.9-6.0)$ & $2.1(1.8-2.4)$ \\
\hline \multicolumn{3}{|c|}{ Newborn ICU (1501-2500 g) } \\
\hline CLAB & $13.9(12.4-15.6)$ & $2.4(1.9-2.9)$ \\
\hline VAP & $9.50(7.9-11.3)$ & $1.0(0.6-0.2)$ \\
\hline
\end{tabular}

control personnel and other healthcare workers. A variety of methods can be used to identify microorganisms in clinical specimens, although in LMIC diagnostic capabilities are insufficient. Partnership between the infection preventionist and the clinical microbiology laboratory staff is crucial in combating against HRIs.

In conclusion, HRIs represent a major threat to patient safety and quality healthcare in low and middle income countries. Through focusing on infection control, countries with limited resources can improve the quality of healthcare in the future. Sustainability of any initiated activities will have a great impact on outcomes.

\section{REFERENCES}

[1] Ponce-de-Leon-Rosales S, Macias A. Global perspectives of infection control. In: Wenzel RP, Ed. Prevention and control of nosocomial infections. $4^{\text {th }}$ ed. Philadelphia- Lippincott Williams \& Wilkins 2003; pp. 14-33.

[2] Burke J. Infection control e a problem for patient safety. N Engl J Med 2003; 348: 651-6.

[3] Ducel G, Fabry J, Nicolle L, et al. Prevention of hospital-acquired infections. A practical guide. World Health Organ 2002; 9.

[4] Corona A, Raimondi F. Prevention of nosocomial infection in the ICU setting. Minerva Anestesiol 2004; 70(5): 329-37.

[5] Horan TC, Emori TG. Definitions of key terms used in the NNIS system. Am J Infect Control 1997; 25: 112-6.

[6] Ramirez JA. Controlling multiple-drug-resistant organisms at the hospital level. Expert Opin Pharmacother 2006; 7(11): 1449-55.

[7] Pittet D, Allegranzi B, Storr J, et al. Infection control as a major World Health Organization priority for developing countries. J Hosp Infect 2008; 68(4): 285-92

[8] World Bank. World Bank Classification of Economies. vol 2008

[9] Lynch P, Pittet D, Borg MA, Mehtar S. Infection control in countries with limited resources. J Hosp Infect 2007; 65: 148-50.

[10] Hambraeus A. Lowbury Lecture 2005: infection control from a global perspective. J Hosp Infect 2006; 64: 217-23.

[11] Lynch P, Rosenthal V, Borg M, Eremin S. Infection control in developing countries. In: Jarvis WR, Ed. Bennett and Brachman's
Hospital Infections. Philadelphia: Lippincott Williams \& Wilkins 2007; pp. 240-55.

[12] Morris K. Global control of health-care associated infections. Lancet 2008; 372: 1941-2.

[13] Duke T, Kelly J, Weber M, English M, Campbell H. hospital care for children in developing countries: clinical guidelines and the need for evidence. J Trop Pediatr 2006; 52(1): 1-2

[14] Clements C, Halton K, Graves N, et al. Overcrowding and understaffing in modern health-care systems: key determinants in meticillin-resistant Staphylococcus aureus transmission. Lancet Infect Dis 2008; 8: 427-34.

[15] Editorial. Blood supply and demand. Lancet 2005; 365: 2151.

[16] Simonsen L, Kane A, Lloyd J, Zaffran M, Kane M. Unsafe injections in the developing world and transmission of bloodborne pathogens: a review. Bull World Health Organ 1999; 77: 789-800.

[17] Miller MA, Pisani E. The cost of unsafe injections. Bull World Health Organ 1999; 77(10): 808-11.

[18] Global patient safety challenge. Clean care is Safe care. World Health Organization 2005.

[19] Hauri AM, Armstrong GL, Hutin YJ. The global burden of disease attributable to contaminated injections given in health care settings. Int J STD AIDS 2004; 15: 7-16.

[20] Centers for Disease Control. Public health focus: surveillance, prevention and control of nosocomial infections. Morb Mortal Wkly Rep 1992; 41: 783-7.

[21] European Center for Disease Control. Commision Disease Report. 2008.

[22] Lynch P, Jackson M, Preston GA, Soule BM. Infection prevention with limited resources. Chicago: ETNA Communications 1997.

[23] Tikhomirov E. WHO program for control of hospital infections. Chemiotherapia 1987; 3: 3148-51.

[24] Rosenthal VD, Maki DG, Jamulitrat S, et al. International Nosocomial Infection Control Consortium (INICC) report, data summary for 2003-2008, issued June 2009. Am J Infect Control 2010; 38(2): 95-104.

[25] Arabi Y, Al-Shirawi N, Memish Z, Anzueto A. Ventilatorassociated pneumonia in adults in developing countries: a systematic review. Int J Infect Dis 2008; 12: 505-12.

[26] Zaidi AK, Huskins WC, Thaver D, et al. Hospital-acquired neonatal infections in developing countries. Lancet 2005; 365: 1175-88. 
[27] Lawn JE, Cousens S, Bhutta ZA, et al. Why are 4 million newborn babies dying each year? Lancet 2004; 364: 399-401.

[28] Jarvis WR. Selected aspects of the socioeconomic impact of nosocomial infections: morbidity, mortality, cost, and prevention. Infect Control Hosp Epidemiol 1996; 17: 552-7.

[29] World Alliance for Patient Safety. Global patient safety e clean care is safer care. Geneva: World Health Organ 2005; 3-16.

[30] Stone PW. Economic burden of healthcare-associated infections: an American perspective. Expert Rev Pharmacoecon Outcomes Res 2009; 9(5): 417-22.

[31] Okeke IN, Laxminarayan R, Bhutta ZA, et al. Antimicrobial resistance in developing countries. Lancet Infect Dis 2005; 8: 48193.

[32] Wenzel RP, Edmond MB. Managing antibiotic resistance. N Engl J Med 2000; 343: 1961-63.

[33] Kollef M. Optimizing antibiotic therapy in intensive care unit setting. Crit Care 2001; 5: 189-95.

[34] Haley RW, Quade D, Freeman HE, Bennet JV. The SENIC project: Study on the Efficacy of Nosocomial Infection Control. Am J Epidemiol 1980; 111: 472-85.

[35] Harbarth S, Sax H, Gastmeier P. The preventable proportion of nosocomial infections: an overview of published reports. J Hosp Infect 2003; 54: 258-66.

[36] Cavalcante MD, Braga OB, Teofilo CH, Oliveira EN, Alves A. Cost improvements through the establishment of prudent infection control practices in a Brazilian general hospital, 1986-1989. Infect Control Hosp Epidemiol 1991; 12: 649-53.

[37] Raza MW, Kazi BM, Mustafa M, Gould FK. Developing countries have their own characteristic problems with infection control. J Hosp Infect 2004; 57: 294-9.

[38] Vagholkar S, Ng J, Chan RC, Bunker JM, Zwar NA. Healthcare workers and immunity to infectious diseases. Aust $\mathrm{N} \mathrm{Z} \mathrm{J} \mathrm{Public}$ Health 2008 ; 32 : 367-71.
[39] Randle J, Clarke M, Storr J. Hand hygiene compliance in healthcare workers. J Hosp Infect 2006; 64: 205-9.

[40] Boyce JM, Pittet D. Guideline for hand hygiene in healthcare settings. Am J Infect Control 2002; 30: 1-46.

[41] Hugonnet S, Perneger TV, Pittet D. Alcohol-based handrub improves compliance with hand hygiene in intensive care units. Arch Intern Med 2002; 62: 1037-43

[42] Rosenthal VD, Guzman S, Safdar N. Reduction in nosocomial infection with improved hand hygiene in intensive care units of a tertiary care hospital in Argentina. Am J Infect Control 2005; 33: 392-7.

[43] Damani N. Surveillance in countries with limited resources. Int J Infect Control 2008; 4: 1 .

[44] Gould IM. A review of the role of antibiotic policies in the contro of antibiotic resistance. J Antimicrob Chemother 1999; 43: 459-65.

[45] Pfaller M, Herwalt L. The clinical microbiology laboratory and infection control: emerging pathogens, antimicrobial resistance and new technology. Clin Infect Dis 1997; 25: 858-70.

[46] Westwell S. Implementing a ventilator care bundle in an adult intensive care unit. Nurs Crit Care 2008; 13: 203-7.

[47] Allegranzi B, Storr J, Dziekan G, et al. The First Global Patient Safety Challenge "Clean Care is Safer Care": from launch to current progress and achievements. J Hosp Infect 2007; 65(Suppl 2): $115-23$

[48] Allegranzi B, Pittet D. Role of hand hygiene in healthcareassociated infection prevention. J Hosp Infect 2009; 73(4): 305-15.

[49] Rutala WA, Weber DJ. Disinfection and sterilization in health care facilities: what clinicians need to know. Clin Infect Dis 2004; 39: 702-9.

[50] Kalenic S, Budimir A. The role of microbiology laboratory in healthcare-associated infection prevention. Int $\mathrm{J}$ Infect Control 2009; v5: i2.

(C) Lul Raka; Licensee Bentham Open.

This is an open access article licensed under the terms of the Creative Commons Attribution Non-Commercial License (http://creativecommons.org/licenses/ by-nc/3.0/) which permits unrestricted, non-commercial use, distribution and reproduction in any medium, provided the work is properly cited. 